Article

\title{
Rice OsAAA-ATPase1 is Induced during Blast Infection in a Salicylic Acid-Dependent Manner, and Promotes Blast Fungus Resistance
}

\author{
Xinqiong Liu ${ }^{1, *+\dagger}$, Haruhiko Inoue ${ }^{2, \dagger}$, Xianying Tang ${ }^{1}$, Yanping Tan ${ }^{1}$, Xin $\mathrm{Xu}^{1}{ }^{1}$, Chuntai Wang ${ }^{1}$ \\ and Chang-Jie Jiang $2, *$ (I) \\ 1 College of Life Science, South-Central University for Nationalities, Wuhan 430074, China; \\ xytang@mail.scuec.edu.cn (X.T.); yanptan@mail.scuec.edu.cn (Y.T.); xinxu@mail.scuec.edu.cn (X.X.); \\ wangchuntai@mail.scuec.edu.cn (C.W.) \\ 2 Institute of Agrobiological Sciences (NIAS), National Agriculture and Food Research Organization (NARO), \\ Tsukuba 305-8602, Japan; haruhiko@affrc.go.jp \\ * Correspondence: liuxinqiong@mail.scuec.edu.cn (X.L.); cjjiang@affrc.go.jp(C.-J.J.); \\ Tel.: +86-189-7122-9082 (X.L.); +81-298-838-8385(C.-J.J.) \\ + These authors contributed equally to this work.
}

Received: 29 January 2020; Accepted: 18 February 2020; Published: 20 February 2020

\begin{abstract}
Fatty acids (FAs) have been implicated in signaling roles in plant defense responses. We previously reported that mutation or RNAi-knockdown (OsSSI2-kd) of the rice OsSSI2 gene, encoding ta stearoyl acyl carrier protein FA desaturase (SACPD), remarkably enhanced resistance to blast fungus Magnaporthe oryzae and the leaf-blight bacterium Xanthomonas oryzae pv. oryzae (Xoo). Transcriptomic analysis identified six AAA-ATPase family genes (hereafter OsAAA-ATPase1-6) upregulated in the OsSSI2-kd plants, in addition to other well-known defense-related genes. Here, we report the functional analysis of OsAAA-ATPase1 in rice's defense response to M. oryzae. Recombinant OsAAA-ATPase1 synthesized in Escherichia coli showed ATPase activity. OsAAA-ATPase1 transcription was induced by exogenous treatment with a functional analogue of salicylic acid (SA), benzothiadiazole (BTH), but not by other plant hormones tested. The transcription of OsAAA-ATPase1 was also highly induced in response to M. oryzae infection in an SA-dependent manner, as gene induction was significantly attenuated in a transgenic rice line expressing a bacterial gene $(n a h G)$ encoding salicylate hydroxylase. Overexpression of OsAAA-ATPase 1 significantly enhanced pathogenesis-related gene expression and the resistance to $M$. oryzae; conversely, RNAi-mediated suppression of this gene compromised this resistance. These results suggest that OsAAA-APTase1 plays an important role in SA-mediated defense responses against blast fungus M. oryzae.
\end{abstract}

Keywords: AAA-ATPase; salicylic acid; fatty acid; rice; Magnaporthe oryzae; disease resistance

\section{Introduction}

Salicylic acid (SA) plays an important signaling role in plant defense activation against pathogens. In response to pathogen attack, SA activates a battery of defense-related genes, including pathogenesis-related (PR) genes, throughout the plant, resulting in both local and systemic resistance to the pathogen [1]. In Arabidopsis, NPR1 (non-pathogenesis related 1) has been demonstrated to play a master role in SA-mediated defense activation [2,3]. A loss of NPR1 function (npr1) results in loss of PR gene induction, and hypersensitivity to diseases [4]. In rice, meanwhile, it has been shown that SA signaling is mediated by two downstream factors, OsNPR1 and WRKY45, acting in parallel $[5,6]$. 
In Arabidopsis, genetic screening for mutations that can suppress npr1 phenotypes (based on their ability to restore SA-induced PR expression to npr1-5 plants) resulted in isolation of several $n p r 1$ suppressor mutants (ssi: suppressor of SA insensitivity), which exhibit constitutive defense activation [7]. Map-based cloning of one of the ssi mutants (ssi2) revealed that the corresponding gene (SSI2) encodes a stearoyl-ACP desaturase, which desaturates stearoyl (18:0)-ACP into oleoyl-ACP, and finally, into oleic acid (18:1) [7]. Disruption of this gene in ssi2 results in a ten-fold increase in 18:0 fatty acid (FA) content, indicating involvement of FAs in plant defense reactions [7]. The ssi2 mutant plants accumulate high levels of SA and display constitutive PR gene expression and enhanced resistance to Peronospora parasitica, Pseudomonas syringae [8], and Cucumber mosaic virus $[7,9,10]$.

The orthologs of SSI2 have also been identified in soybean (GmSACPD-A/-B) [11], rice (OsSSI2) [12], and wheat (TaSSI2) $[13,14]$. Similar to Arabidopsis ssi2, suppression of these ortholog genes enhanced resistance to multiple pathogens: Pseudomonas syringae pv. glycinea and Phytophthora sojae in soybean [11]; blast fungus Magnaporthe oryzae and leaf-blight bacteria Xanthomonas oryzae pv. oryzae (Xoo) in rice [12]; and powdery mildew bacteria Blumeria graminis f. sp. tritici and Fusarium head blight fungus Fusarium graminearum in wheat $[13,14]$. These results demonstrate a common function of SSI2 and its orthologs in defense activation in diverse plant species.

The molecular mechanisms whereby the SSI2 family genes participate in defense reactions in plants remain to be fully elucidated. In rice, a DNA microarray analysis revealed several hundred genes differentially expressed between the wild-type and OsSSI2-suppressed transgenic (OsSSI2-kd) plants [12]. Among them was a group of six genes for AAA-ATPase (AAA: ATPases associated with diverse cellular activities) highly upregulated in OsSSI2-kd plants, in addition to the well-known defense-related genes, such as WRKY45, PR1b, and PBZ1, and a thaumatin-like gene [12]. These results suggest that the AAA-ATPase family genes may play important roles in defense activation in rice plants.

The AAA-ATPase family occurs in all life forms, including eukaryotes, prokaryotes, and archaebacteria, and is implicated in a variety of cellular activities, including proteolysis, protein folding, membrane trafficking, cytoskeletal regulation, organelle biogenesis, DNA replication, and immune responses [15-17]. Structurally, these proteins contain one or several conserved motifs, including the Walker A and Walker B motifs, which are, respectively, required for ATP binding and hydrolysis; they also contain a highly conserved amino acid sequence, referred to as the second region of homology (SRH) [16]. In plants, it has been reported that AAA-ATPase genes from Nicotiana tabacum (NtAAA1) [18,19] and Arabidopsis (AtOM66) [20] are, respectively, negatively or positively involved in the SA-signaling pathway and in the hypersensitive response (HR) upon pathogen infections. Moreover, in rice, map-based cloning of the lesion mimic resembling $(\mathrm{lmr})$ mutant/lesion resembling disease (lrd6-6) mutant revealed that the corresponding gene (LMR/LRD6-6, Os06g0130000) encodes an AAA-ATPase, and is negatively involved in HR and disease resistance $[21,22]$.

In this study, we conducted a functional analysis of OsAAA-ATPase1, one of the six AAA-ATPase genes upregulated in OsSSI2-kd rice plants [12]. We show that OsAAA-ATPase1 is transcriptionally regulated by SA, and positively involved in resistance to blast fugus $M$. oryzae.

\section{Results}

In our previous study, a group of six AAA-ATPase family genes (hereafter OsAAA-ATPase1-6; (Table 1; Figure 1) was found to be significantly upregulated in OsSSI2-kd rice plants [12], implicating these genes in rice defense activation. From among them, we chose OsAAA-ATPase 1 for more detailed functional characterization in this study, because it showed SA-induced (Figure 2) and SA-dependent blast-induced (Figure 3) transcription responses. 
Table 1. Genes and primer sequences used for qRT-PCR analysis.

\begin{tabular}{|c|c|c|}
\hline $\begin{array}{l}\text { Gene Name } \\
\text { (RAP+DB ID) }\end{array}$ & Primer Sequences $\left(5^{\prime} \rightarrow 3^{\prime}\right)$ & References \\
\hline $\begin{array}{l}\text { OsAAA-ATPase } 1 \\
\text { Os03g0802500 }\end{array}$ & $\begin{array}{l}\text { AGTGGTTGCTAGCTTCTCGT } \\
\text { ACAACATGTGGTCAAATTATTCCA }\end{array}$ & [12] \\
\hline $\begin{array}{l}\text { OsAAA-ATPase2 } \\
\text { Os01g0297200 }\end{array}$ & $\begin{array}{l}\text { CTAGGTTCTGCGATGGACAC } \\
\text { CTCCTTTGCAATTGTTCCAC }\end{array}$ & [12] \\
\hline $\begin{array}{l}\text { OsAAA-ATPase3 } \\
\text { Os06g0697600 }\end{array}$ & $\begin{array}{l}\text { GTTGTGATCGTGTCATGGTTGCG } \\
\text { CAGAAAGCCACACACCATTGC }\end{array}$ & [12] \\
\hline $\begin{array}{l}\text { OsAAA-ATPase4 } \\
\text { Os02g0697600 }\end{array}$ & $\begin{array}{l}\text { TTGCCTGAACGGCCAGGTGAT } \\
\text { CCCATGTAAGGGTAAGGATTGC }\end{array}$ & [12] \\
\hline $\begin{array}{l}\text { OsAAA-ATPase5 } \\
\text { Os02g0706500 }\end{array}$ & $\begin{array}{l}\text { GTTCCATCTCTTTGCCTGTAGC } \\
\text { CATGCGCATCTCAGTCTTACC }\end{array}$ & [12] \\
\hline $\begin{array}{l}\text { OsAAA-ATPase6 } \\
\text { Os07g0517600 }\end{array}$ & $\begin{array}{l}\text { TCAGTGGCCTCGTCGAGTTC } \\
\text { CTACTTGCCTGCTTCACACAT }\end{array}$ & [12] \\
\hline $\begin{array}{l}\text { OsPR1b } \\
\text { Os01g0382000 }\end{array}$ & $\begin{array}{l}\text { ACGGGCGTACGTACTGGCTA } \\
\text { CTCGGTATGGACCGTGAAG }\end{array}$ & [23] \\
\hline $\begin{array}{l}\text { PBZ1 } \\
\text { Os12g0555000 }\end{array}$ & $\begin{array}{l}\text { GCGTTTGAGTCCGTGAGAGT } \\
\text { TCACCCATTGATGAAGCAAA }\end{array}$ & [24] \\
\hline $\begin{array}{l}\text { Rubq1 } \\
\text { Os06g0681400 }\end{array}$ & $\begin{array}{l}\text { GGAGCTGCTGCTGTTCTAGG } \\
\text { TTCAGACACCATCAAACCAGA }\end{array}$ & [25] \\
\hline $\begin{array}{l}\text { M. oryzae } \\
28 \mathrm{~S} \text { rDNA }\end{array}$ & $\begin{array}{l}\text { ACGAGAGGAACCGCTCATTCAGATAATT } \\
\text { TCAGCAGATCGTAACGATAAAGCTACTC }\end{array}$ & [26] \\
\hline
\end{tabular}

\subsection{OsAAA-ATPase1 Encodes an AAA-ATPase Family Protein}

OsAAA-ATPase 1 was predicted to encode a protein of 520 amino acids with a predicted mass of 58.1 $\mathrm{kDa}$. OsAAA-ATPase1 shared $50 \%, 37.8 \%$, and $22.3 \%$ amino acid sequence identity with previously reported defense-related AAA-ATPase proteins, namely, tobacco NtAAA1 [18], Arabidopsis AtOM66 [20], and rice LMR/LRD6-6 [21,22], respectively. Structural analysis revealed that OsAAA-ATPase1 contains consensus motifs that are typical of the AAA-ATPase family; these include the Walker A, Walker B, and SRH motifs (pfam00004; E-value $=4.95 \times 10^{-17}$ ) (Figure 1a).

To assess how OsAAA-ATPase1-6 are related within the AAA-ATPase gene family, we performed a phylogenic comparison of the proteins predicted to be encoded by OsAAA-ATPase1-6 and several known rice AAA-ATPase proteins, including LMR/LRD6-6 [21,22], OsCDC48 [27], RuvBL1a [28], RLS3 [29], OsSKD1 [30], OsFtsH5 [31], and RFC5 [32], together with NtAAA1 [18,19] and AtOM66 [20]. OsAAA-ATPase1 was grouped within a subclade of proteins related to plant defense, including OsAAA-ATPase2-6, NtAAA1, and AtOM66, but, unexpectedly, distally with LMR/LRD6-6 (Figure 1b). 
(a)

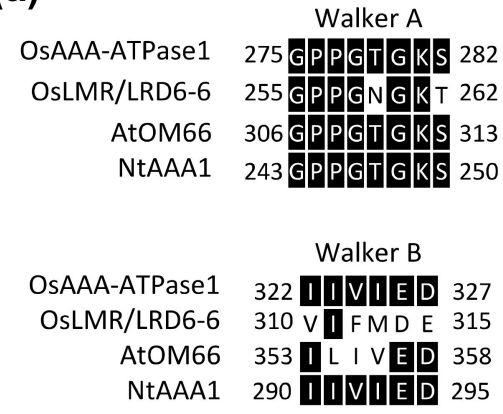

Second Region of Homology

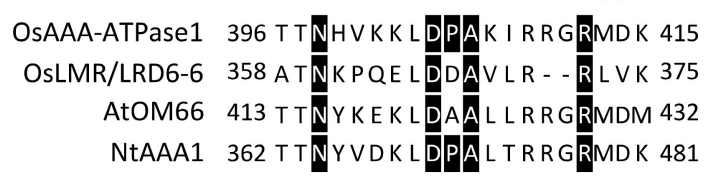

(b)

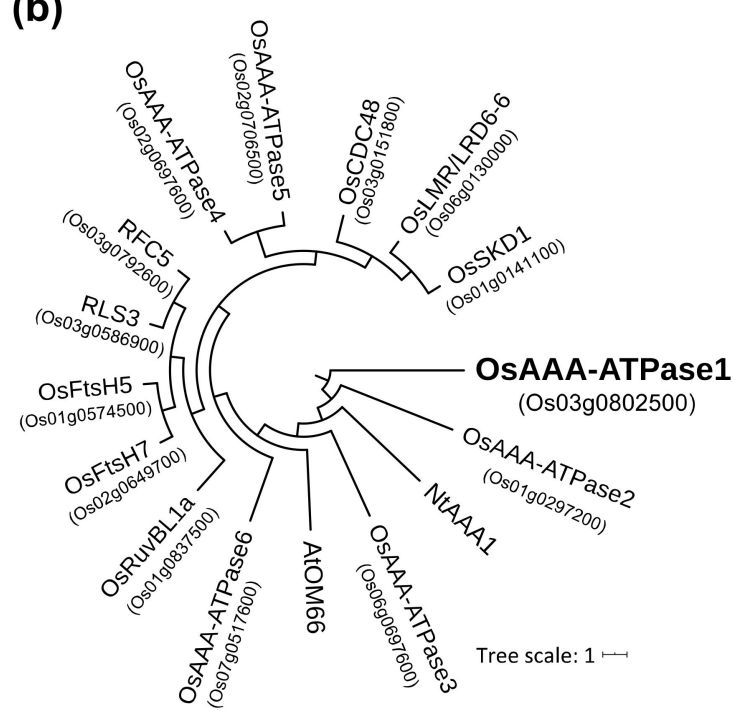

Figure 1. Amino acid sequence alignment of AAA-type ATPase proteins, and phylogenetic analysis. (a) Alignment of typical consensus motifs of the AAA-ATPase protein family, including the Walker A, Walker B, and SRH motifs. (b) Phylogeny of the AAA-ATPase proteins from rice (LMR/LRD6-6, OsCDC48, RuvBL1a, RLS3, OsSKD1, OsFtsH5, and RFC5), tobacco (NtAAA1), and Arabidopsis (AtOM66). 
(a)

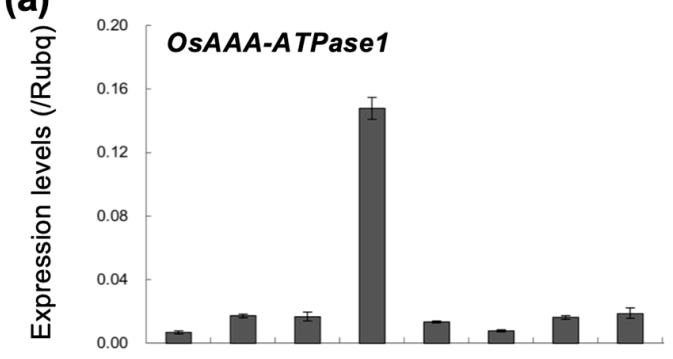

(b)

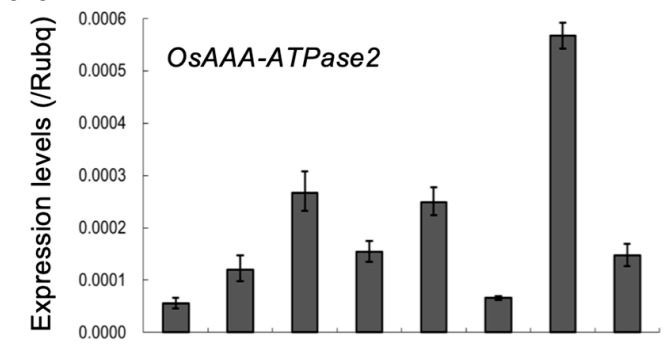

(c)

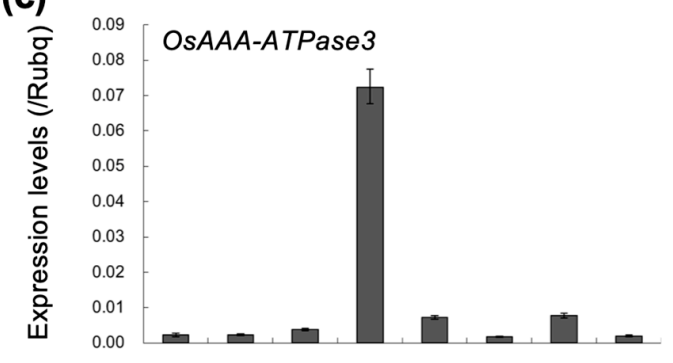

(d)

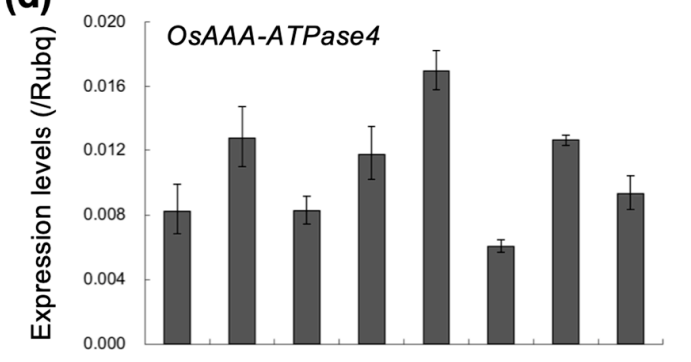

(e)

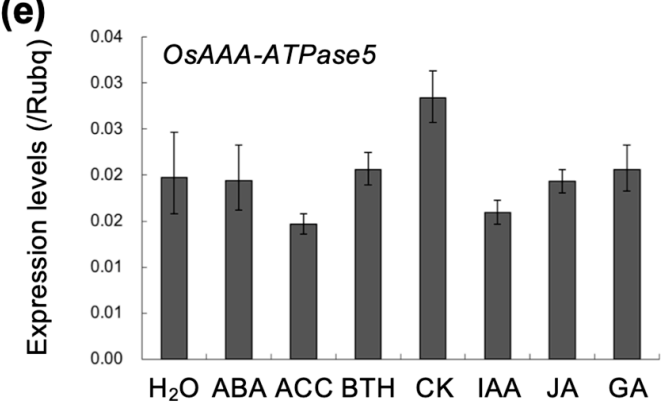

Figure 2. Expression analysis of OsAAA-ATPase1-5 (a-e) in response to the plant hormones abscisic acid (ABA), ethylene (ACC, an ethylene precursor), benzothiadiazole (BTH, a functional analogue of SA), kinetin (CK, a synthetic cytokinin), auxin (IAA), jasmonic acid (JA), and gibberellic acid (GA), in Nipponbare rice seedlings. Data are represented as means \pm SDs. 
(a)

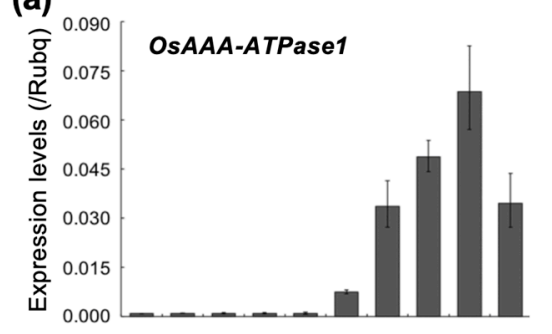

(c)

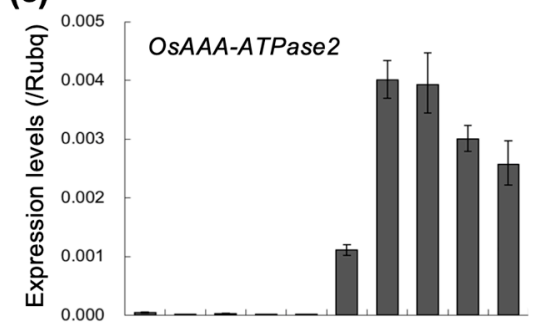

(e)

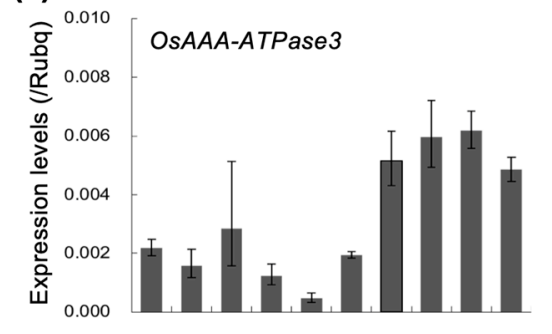

(g)

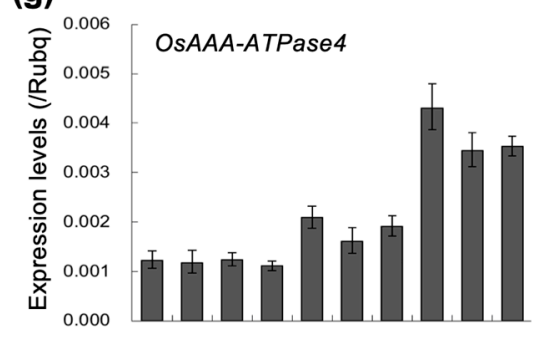

(i)

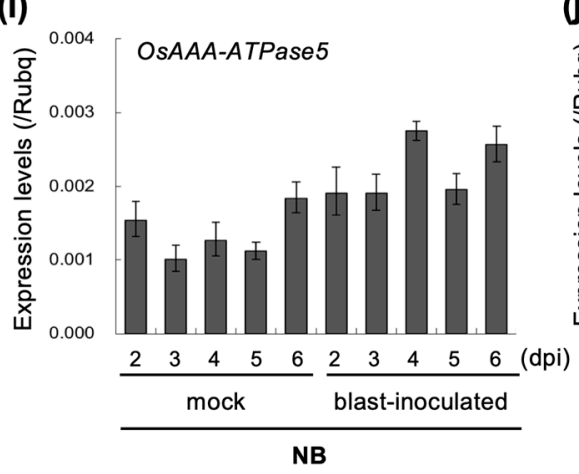

(b)

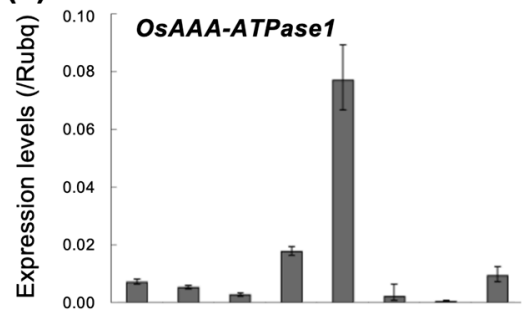

(d)

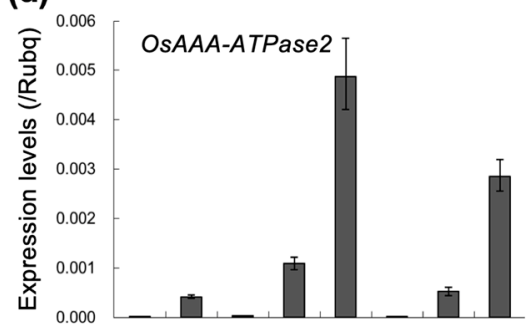

(f)

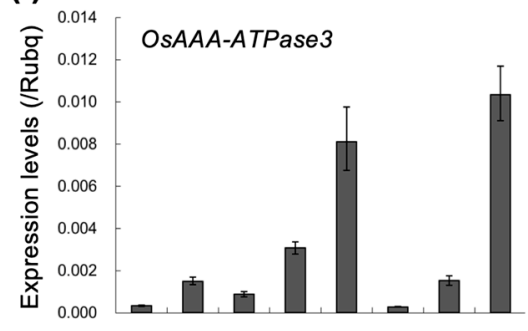

(h)

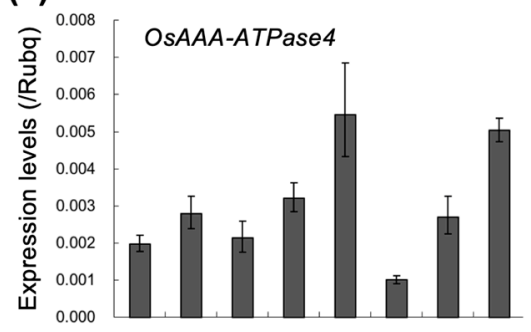

(j)

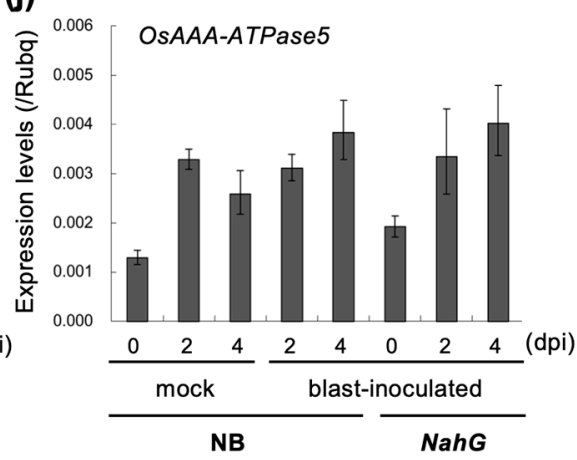

Figure 3. Expression analysis of OsAAA-ATPase1-5 (a-j) in response to blast inoculation in Nipponbare (NB) and narG rice seedlings. Rice seedlings at the four-leaf stage (three true leaves) were subjected to mock treatment (mock) or blast inoculation (blast-inoculated), and the fourth leaf blades were sampled at indicated days post inoculation (dpi). Data are represented as means \pm SDs. 


\subsection{OsAAA-ATPase1 is Induced by SA Treatment}

Plant hormones have been demonstrated to play important roles in interactions between plants and pathogens. Hence, we examined the transcriptional responses of OsAAA-ATPase1-6 to the plant hormones abscisic acid (ABA), ACC (an ethylene precursor), BTH (a functional analogue of SA), kinetin (CK, a synthetic cytokinin), auxin (IAA), jasmonic acid (JA), and gibberellic acid (GA).

OsAAA-ATPase1 (Figure 2a) and OsAAA-ATPase3 (Figure 2c) were induced specifically by BTH treatment, and OsAAA-ATPase2 (Figure 2b) was induced by JA treatment. Meanwhile, OsAAA-ATPase4 (Figure 2d) and OsAAA-ATPase5 (Figure 2e) were not specifically induced by any of the hormones, and OsAAA-ATPase6 (Os07g0517600) had no detectable transcription.

\subsection{OsAAA-ATPase1 is Induced in Response to Blast Infection in An SA-Dependent Manner}

Rice seedlings of non-transformant Nipponbare rice (NB) and of NB expressing the nah $G$ gene (nahG-rice), at the four-leaf stage, were subjected to blast inoculation. At 2-6 days post inoculation (dpi) of the blast, the fourth leaves were sampled to examine the expression of OsAAA-ATPase1-5.

All of the tested OsAAA-ATPase genes clearly showed transcriptional induction in response to blast inoculation (Figure 3c,e,g,i); in particular, OsAAA-ATPase1 (Figure 3a) and OsAAA-ATPase2 (Figure $3 c$ ) showed a high-fold transcriptional increase from the very low basal levels in the mock treatment. The induction of the genes became evident from $2 \mathrm{dpi}$ and peaked at ca. 3-5 dpi.

In nah G-rice plants, in contrast, the induction of OsAAA-ATPase1 was mostly attenuated relative to its induction in NB plants in response to blast inoculation (Figure 3b), demonstrating that the induction of this gene depends on the SA-signaling pathway. No appreciable attenuation of gene induction was observed for the other genes (Figure $3 \mathrm{~d}, \mathrm{f}, \mathrm{h}, \mathrm{j}$ ).

\subsection{OsAAA-ATPase1 is Positively Involved in Blast Resistance}

To gain some insight into the role of OsAAA-ATPase1 in disease resistance, we generated transgenic rice lines that either overexpressed the gene under maize ubiquitin promoter (OsAAA-ATPase1-ox; Figure 4a) or RNAi-suppressed OsAAA-ATPase1 (OsAAA-ATPase1-kd; Figure 5a), and subjected these lines to blast inoculation. In order to reveal the potentially compromised resistance in OsAAA-ATPase1-kd plants, a half density of conidia $\left(5 \times 10^{4} / \mathrm{mL}\right)$ was used, so as to cause blast disease moderately in NB, but more severely in OsAAA-ATPase1 plants. 
(a)

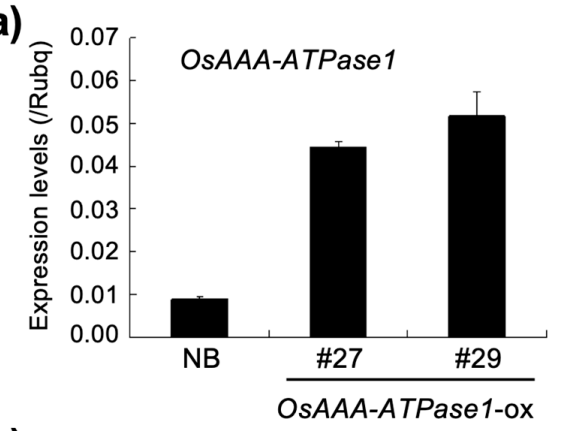

(b)

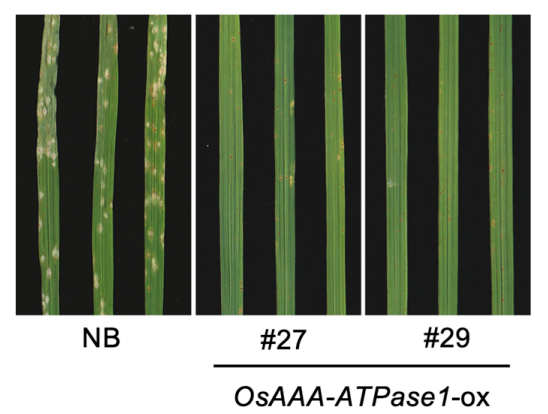

(c)

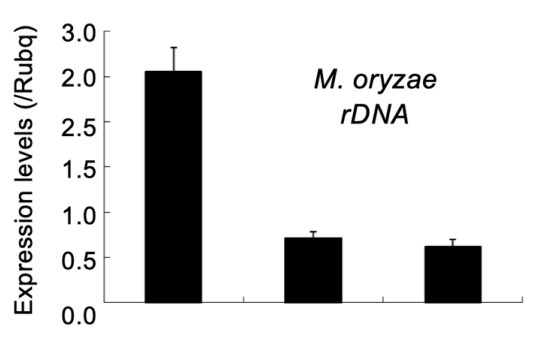

(d)

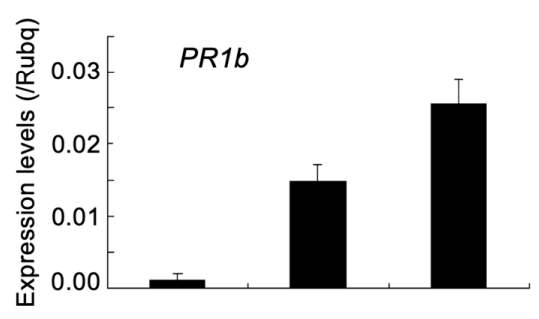

(e)

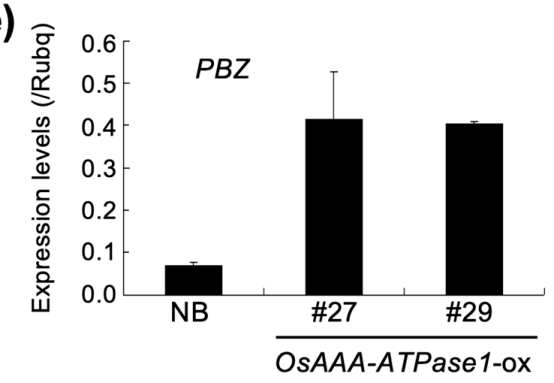

Figure 4. Blast resistance of OsAAA-ATPase1-ox plants. (a) Expression of OsAAA-ATPase1, (b) blast lesions on leaf blades, and (c) relative fungal growth (Magnaporthe oryzae $r D N A)$. (d,e) Expression of PR1b (d) and PBZ1 (e), in Nipponbare (NB) and OsAAA-ATPase1-ox lines (\#27 and \#29), respectively, at 7 days post inoculation (dpi). Data are represented as means \pm SDs in $(\mathbf{a}, \mathbf{c}-\mathbf{e})$. 
(a)

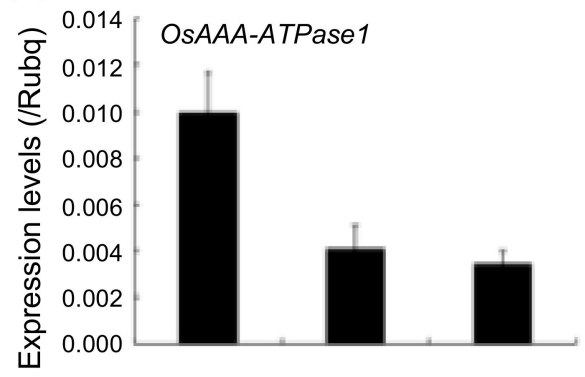

(b)

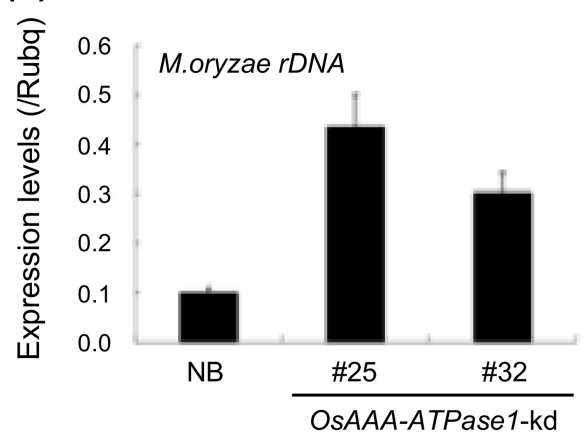

Figure 5. Compromised blast resistance in OsAAA-ATPase1-kd plants (\#25 and \#32). (a) Expression of OsAAA-ATPase1. (b) Relative fungal growth (M. oryzae $r D N A)$ in Nipponbare (NB) and OsAAA-ATPase1-kd lines (\#25 and \#32) respectively. Data are represented as means \pm SDs.

Compared with the non-transgenic control plants (NB), OsAAA-ATPase1-ox plants (lines \#27 and \#29) exhibited significantly higher resistance to blast disease, as evidenced by the fact that few susceptible blast lesions appeared on their leaf blades (Figure $4 \mathrm{~b}$ ), and that they had ca. 4-fold less fungal growth (Figure 4c). The enhanced resistance of the OsAAA-ATPase1-ox plants is consistent with the large increases in the expression levels of the PR genes, OsPR1 and PBZ1 (Figure 4d,e).

Conversely, blast resistance was significantly compromised in OsAAA-ATPase1-kd plants (lines \#25 and \#32): they had ca. 2-fold more fungal growth than the NB control plants (Figure 5b).

\subsection{OsAAA-ATPase1 Has ATPase Activity and Is Localized in the Cytosol}

To assess whether OsAAA-ATPase1 protein has ATPase activity, OsAAA-ATPase1 N-terminal was fused to a His-tag and expressed in Escherichia coli, and purified using a high affinity Ni-resin. OsAAA-ATPase1 protein showed an ATPase activity level that was comparable to that of the positive control (potato ATPase) (Figure 6).

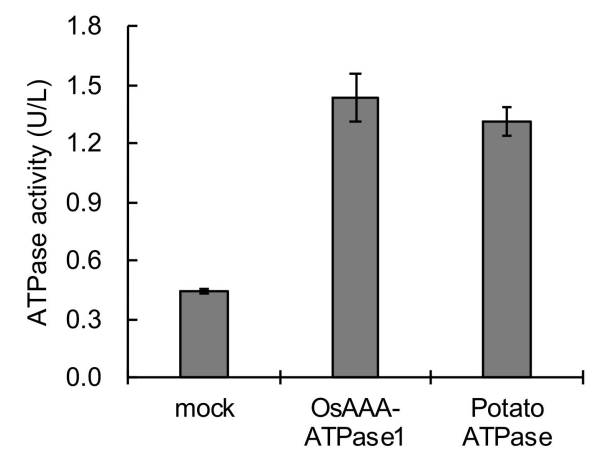

Figure 6. ATPase activity of recombinant OsAAA-ATPase1 protein. Elution buffer of Ni-resin (mock treatment), and an ATPase protein from potatoes, were used negative and positive controls, respectively. 
To determine the subcellular localization of OsAAA-ATPase1 in rice cells, the EGFP-OsAAAATPase1 fusion protein in the rice protoplast was examined under a confocal microscope. As shown in Figure 7, EGFP-OsAAA-ATPase1 protein was co-localized with a cytosol marker, mCherry signals, indicating that OsAAA-ATPase is predominantly distributed in the cytosol.

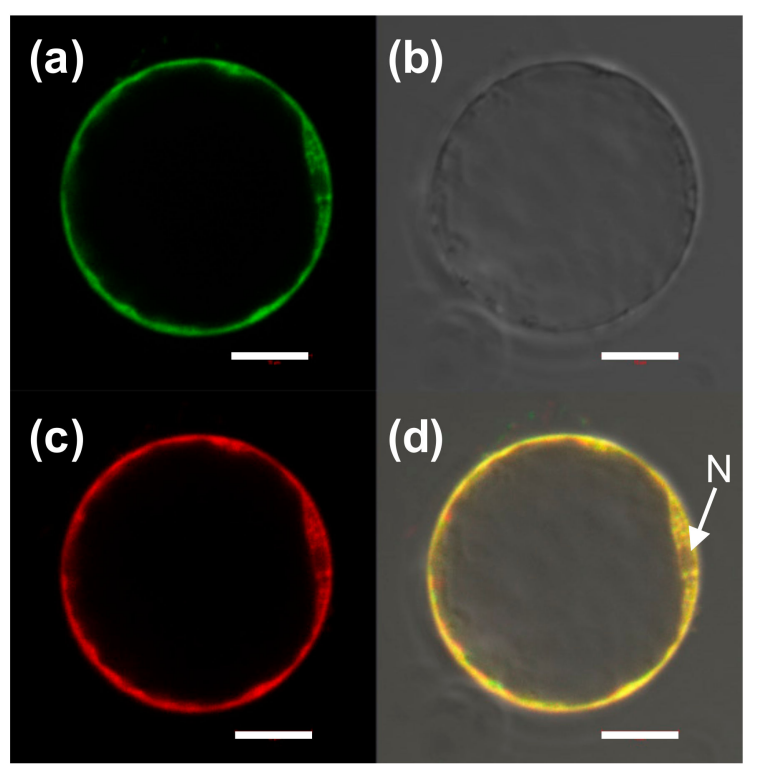

Figure 7. Subcellular localization of OsAAA-ATPase1 in rice protoplasts. (a) EGFP-OsAAA-ATPase1, (b) blight field image, (c) mCherry (cytoplasmic localization), and (d) combined image of (a-c). N, nucleus; bar, $20 \mu \mathrm{m}$.

\section{Discussion}

AAA-type ATPases constitute a large protein family in a diverse range of organisms, and thus exhibit multiple and diverse cellular functions [15,33]. In plants, AAA-ATPase genes have been implicated in proteolysis [33], male meiosis [34], vacuolar maintenance [35], peroxisome biogenesis [36], morphogenesis [37], leaf senescence [29,38], and stress [28,39] and immune responses [18-22]. In this study, we present a novel rice AAA-ATPase gene member, OsAAA-ATPase1. The deduced amino acid sequence of OsAAA-ATPase1 contains consensus motifs that are typical of the AAA-ATPase family; these include the Walker A, Walker B, and SRH motifs (Figure 1a) [15,17,33]. Consistent with this, biochemical analysis confirmed that there was ATPase activity in the recombinant protein of OsAAA-ATPase1 (Figure 6). Phylogenetically, OsAAA-ATPase1 was grouped within a subclade of proteins related to plant defense activation (Figure 1b), which included OsAAA-ATPase2-6 [12], tobacco NtAAA1 [18,19], and Arabidopsis AtOM66 [20]. These results suggest that OsAAA-ATPase1 belongs to the AAA-ATPase family. Functional analysis revealed that OsAAA-ATPase1 is transcriptionally regulated by $S A$ in response to blast infection (Figures 2 and 3 ). Overexpression or RNAi-mediated suppression of OsAAA-ATPase1 resulted, respectively, in an increase (Figure 4) or decrease (Figure 5) in blast resistance. Taken together, our results suggest that OsAAA-ATPase1 plays a positive role in the SA-mediated disease resistance in rice plants.

In relation to plant immune responses, several studies have shown important roles for AAA-ATPase genes. NtAAA1 was isolated as an HR-induced gene in Nicotiana tabacum [18]; was found to be under the control of $N$-gene, ethylene, and jasmonate; and was localized in the cytoplasm. It was also negatively involved in the SA-signaling pathway and pathogen resistance [18,19]. In contrast, AtOM66 (outer mitochondrial membrane protein of $66 \mathrm{kDa}$ ) is a stress-induced gene; overexpression of this gene increased SA content, accelerated cell death rates, and enhanced resistance to the biotrophic pathogen Pseudomonas syringae [20]. Recently, rice LMR and LRD6-6 were map-based cloned from lesion mimic mutants $l m r$ and $l r d 6-6$, respectively, and were found to be the same gene (Os06g0130000). 
LMR/LRD6-6 was shown to be localized in the multivesicular bodies (MVBs) and was negatively involved in rice immunity and cell death [21,22]. Mutation in this gene (lmr and $l r d 6-6)$ resulted in constitutive expression of $P R 1$ and PBZ1, and enhanced resistance to rice blast and bacterial blight diseases; however, no difference in SA content was determined [21,22]. By comparison, it seems that OsAAA-ATPase1 plays a role distinct from those previously reported, with respect to its association with SA-regulation and HR, its subcellular localization, and its promotion of disease resistance. Thus, our findings provide novel insights into SA-regulated defense activation in rice. Meanwhile, OsAAA-ATPase1 showed a close phylogenetic association with AtOM66 (Figure 1b); both proteins play a positive role in the SA-signaling pathway, suggesting that they may share a common cellular function.

Plants produce a variety of FAs and their derivatives, some of which have been shown to play important roles in defense activation [40,41]. In the Arabidopsis ssi2 mutant, disruption of SSI2, which encodes an FA desaturase, results in an increase in the 18:0 FA content, which in turn remarkably increases SA content, PR gene expression, and resistance against multiple pathogens [42]. Similar defense-related phenotypes were observed following suppression of SSI2-orthologs in soybean (GmSACPD-A/-B) [11], rice (OsSSI2) [12], and wheat (TaSSI2) [13,14]. These results strongly suggest that $S S I 2$ and its orthologs serve as valuable susceptibility gene ( $S$ gene) resources for the development of crop cultivars with resistance to multiple pathogens, by employing targeted mutation and genome editing technologies [43-45]. In order to make such successful use of these genes in resistance breeding, it is important to understand the molecular mechanisms underlying the defense activation. In Arabidopsis, a mutation in the GTPase nitric oxide associated 1 (NOA1) gene partially restored the ssi2 phenotype, whereas double mutations in NOA1 and either one of the two nitrate reductase isoforms (NIA1 and NIA2) completely restored the ssi2 phenotypes; this indicates that nitric oxide (NO) is required for constitutive defense in the ssi2 mutant [46,47]. Nevertheless, little has been reported regarding the molecular basis of defense activation in OsSSI2-kd rice plants. We previously identified a group of six AAA-ATPase genes (OsAAA-ATPase1-6) that were upregulated in OsSSI2-kd rice plants [12]. In this study, all of these genes tested were induced in response to blast inoculation (Figure 3), suggesting that they each play a role in resistance to blast fungus. In contrast, OsAAA-ATPase1-5 each exhibited a distinct induction pattern in response to different plant hormone treatments (Figure 2); OsAAA-ATPase1 and OsAAA-ATPase 3 were induced by SA, OsAAA-ATPase 2 mainly by JA, and OsAAA-ATPase4 and OsAAA-ATPase 5 slightly by the CK treatment. These results suggest that there is functional differentiation among the OsAAA-ATPase1-6 genes downstream of OsSSI2 in disease resistance. Moreover, although both OsAAA-ATPase1 and OsAAA-ATPase 3 were induced by SA treatment, only the induction of OsAAA-ATPase1 was attenuated following blast infection in nah G-rice plants (Figure 3). One possible explanation for this is that OsAAA-ATPase3 may be more sensitive to SA, allowing it to be induced even by a residual increase in the SA-signaling level in $n a h G$-rice plants.

\section{Materials and Methods}

\subsection{Plant Materials and Growth Conditions}

Japonica type rice cultivar Nipponbare (Oryza sativa L.) was grown in commercial nursery soil (Bonsol Number 2; Sumitomo Chemical Corp., Tokyo, Japan) in a greenhouse at $28{ }^{\circ} \mathrm{C}$ (day)/ $23^{\circ} \mathrm{C}$ (night) with ca. $50 \%$ relative humidity.

\subsection{Plasmid DNA Construction and Rice Transformation}

The cDNA clone for OsAAA-ATPase1 was provided by the Rice Genome Resource Center, Japan (accession number: AK070731). To construct a plasmid for constitutive expression of OsAAA-ATPase1 under the maize ubiquitin promoter, a DNA fragment containing a $91 \mathrm{bp}$ upstream sequence followed by the full coding sequence of OsAAA-ATPase1 (nucleotides 2-1655) was amplified by PCR and cloned into the pUCAP/Ubi-NT vector, as previously described [5]. To construct a plasmid for OsAAA-ATPase1 
RNAi (OsAAA-ATPase1-kd), part of the 3'-UTR (nucleotides 1543-1845) of OsAAA-ATPase1 cDNA was amplified by PCR and cloned into the pANDA vector, as previously described [48,49].

Nipponbare rice plants were transformed by an Agrobacterium tumefaciens (strain EHA105) mediated technique, as described earlier [50]. Transgenic rice lines expressing nah $G$ from Pseudomonas putida under the control of a double 35S promoter (nah G-rice) were generated using the plant expression construct previously described in Yang et al. [51].

\subsection{Chemical Treatments}

All stock solutions were prepared at a concentration of $100 \mathrm{mmol} / \mathrm{L}$. Indole-3-acetic acid (IAA; Sigma, St. Louis, MO, USA), gibberellin A3 (GA 3 ; Wako, Osaka, Japan), abscisic acid (( \pm )-cis-trans, ABA; Sigma), and methyl jasmonate (ME-JA; Wako, Saitama, Japan) were dissolved in ethanol. Kinetin (Sigma) and benzothiadiazole S-methyl ester (BTH; Wako) were dissolved in dimethyl sulfoxide (DMSO); and 1-aminocyclopropane-1-carboxylic acid (ACC; Sigma) and sodium salicylate (SA; Nacalai Tesque, Tokyo, Japan) were dissolved in $\mathrm{H}_{2} \mathrm{O}$. The solvents did not exceed a final concentration of $0.1 \%$ in the solutions used for plant treatments, and had no effect on the expression of the rice genes examined in this study.

For plant treatments, rice seedlings at the four-leaf stage (three true leaves) were transferred to a container containing each of the plant hormone solutions at $50 \mu \mathrm{M}$. The rice seedlings were further grown for 1 day, and fourth leaf blades were stored in liquid nitrogen for RNA preparation.

\subsection{Protein Expression, Purification, and ATPase Assay}

The OsAAA-ATPase1 sequence was amplified by PCR and cloned into the sites between BgII and HidIIIp of pET32a (Novagen) as a His-tag fusion protein; then, that was transfected into the Escherichia coli Origami strain BL21(Lys). The set of primers used was as follows: OsAAA1BgIII 5'-GTAGATCTCTTGAGACAAATGGAGGCGACG-3'; OsAAA1HindIII $5^{\prime}$-GCTAAGCTTCTACTTATCCTTCCCGACCAC-3'. Expression of the protein was induced for $4 \mathrm{~h}$ at $25{ }^{\circ} \mathrm{C}$ with $0.5 \mathrm{mmol} / \mathrm{L}$ isopropyl $\beta$-D-1-thiogalactopyranoside. Escherichia coli cells were pelleted by centrifugation, resuspended in lysis buffer $(20 \mathrm{mmol} / \mathrm{L}$ Tris- $\mathrm{HCl} \mathrm{pH} 7.4,0.1 \mathrm{M} \mathrm{NaCl}$, $10 \mathrm{mmol} / \mathrm{L}$ imidazole), and sonicated. After the cell debris was removed by centrifugation $(12,000 \times$ $\mathrm{g}, 10 \mathrm{~min}, 4^{\circ} \mathrm{C}$ ), the supernatant was loaded onto a High Affinity Ni-Charged Resin (GE Healthcare, Buckinghamshire, UK), washed with washing buffer $(20 \mathrm{mmol} / \mathrm{L}$ Tris- $\mathrm{HCl} \mathrm{pH} 7.4,0.1 \mathrm{M} \mathrm{NaCl}$, $10 \mathrm{mmol} / \mathrm{L}$ imidazole), and eluted with elution buffer $(20 \mathrm{mmol} / \mathrm{L}$ Tris- $\mathrm{HCl} \mathrm{pH}$ 7.4, $0.1 \mathrm{M} \mathrm{NaCl}$, $180 \mathrm{mmol} / \mathrm{L}$ imidazole). ATPase activity was measured by the malachite green-based colorimetric method using the QuantiChrom ${ }^{\text {TM }}$ ATPase/GTPase activity assay kit (Sigma-Aldrich, St. Louis, MO, USA). The elution buffer was used as the negative control, and an ATPase from potatoes (Sigma-Aldrich, St. Louis, MO, USA) was used as the positive control. One unit is defined as the amount of enzyme that catalyzes the production of $1 \mu \mathrm{M}$ of free phosphate per minute under the assay conditions.

\subsection{Subcellular Localization}

For subcellular localization of OsAAA-ATPase1, the plasmid pSAT6-AFP-C1-OsAAA1 was transformed into protoplasts prepared from etiolated seedlings as previously described [52]. As a control for cytoplasmic localization, the pSAT-mCherry construct was co-transformed. Fluorescence was examined under a confocal microscope (Leica Microsystems, Wetzlar, Germany) $16 \mathrm{~h}$ after transformation.

\subsection{Pathogen Culture and Inoculations}

Culture and inoculation of the blast fungus M. oryzae (compatible race 007.0) was conducted essentially as previously described [12], with slight modifications. Briefly, the fungus was grown on an oatmeal agar medium ( $30 \mathrm{~g} / \mathrm{L}$ oatmeal, $5 \mathrm{~g} / \mathrm{L}$ sucrose, and $16 \mathrm{~g} / \mathrm{L}$ agar) at $26^{\circ} \mathrm{C}$ for $10-12$ day. After removing the aerial hyphae by washing with distilled water and a brush, conidia formation was 
induced by irradiation under continuous black blue light (FL15BLB; Toshiba, Osaka, Japan) at $24{ }^{\circ} \mathrm{C}$ for 3 day. The conidia were suspended in $0.02 \%$ Silwet L-77 (a non-ionic surfactant; Nihon Unica, Tokyo, Japan) at a density of $10^{5} / \mathrm{mL}$, and were sprayed onto rice plants at the four-leaf stage. After incubation in a dew chamber at $24{ }^{\circ} \mathrm{C}$ for $24 \mathrm{~h}$, the rice plants were moved back to the greenhouse.

Disease development was evaluated by determining the M. oryzae genomic $28 \mathrm{~S} r \mathrm{DNA}$ [26] by qRT-PCR [5,6], 6-7 dpi. At least 20 plants were used for each disease assay.

\subsection{RNA Analyses}

Total RNA was isolated from leaf blades of the 4th leaves of rice seedlings using the Trizol reagent (Invitrogen, Carlsbad, CA, USA). Quantitative RT-PCR (qRT-PCR) was performed on a Thermal Cycler Dice TP800 system (Takara Bio, Tokyo, Japan) using SYBR premix Ex Taq mixture (Takara Bio) as previously described [5]. The primer sequences used for qRT-PCR are listed in Table 1.

\subsection{Amino Acid Sequence Alignment and Phylogenetic Analysis}

The protein sequences were retrieved from the rice annotation project database (rap- $\mathrm{db}$ ) and aligned using Clustal- $X$ software, and the tree was constructed using iTOL software [53].

\section{Conclusions}

In this study, we present a novel AAA-ATPase member gene, OsAAA-ATPase1, one of the six AAA-ATPase genes upregulated in OsSSI2-kd rice plants [12]. Functional analysis revealed that OsAAA-ATPase1 is transcriptionally regulated by SA, and plays a positive role in the SA-mediated disease resistance in rice plants. Our findings provide novel insights into SA-regulated defense activation in rice, and the molecular basis of defense activation in OsSSI2-kd rice plants.

Author Contributions: Conceived and designed the experiments: X.L. and C.-J.J. Performed the experiments and analyzed the data: X.L., H.I., X.T., Y.T., X.X., and C.W. Interpreted and wrote the manuscript, H.I. and C.-J.J. All authors have read and agreed to the manuscript as written.

Funding: This work was supported by the National Natural Science Foundation of China (31370306), and grants from Japan's Society for the Promotion of Science (JSPS) KAKENHI to C.J. (19K06065) and to H.I. (17K07678).

Acknowledgments: We thank the NARO Genebank for providing the cDNA clone of OsAAA-ATPase1 (Os03g0802500).

Conflicts of Interest: The authors declare no conflict of interest.

\section{References}

1. Klessig, D.F.; Choi, H.W.; Dempsey, D.M.A. Systemic acquired resistance and salicylic acid: Past, present, and future. Mol. Plant Microbe Interact. 2018, 31, 871-888. [CrossRef] [PubMed]

2. Dong, X. NPR1, all things considered. Curr. Opin. Plant Biol. 2004, 7, 547-552. [CrossRef]

3. Wang, D.; Amornsiripanitch, N.; Dong, X. A genomic approach to identify regulatory nodes in the transcriptional network of systemic acquired resistance in plants. Plos Pathog. 2006, 2, e123. [CrossRef]

4. Cao, H.; Glazebrook, J.; Clarke, J.D.; Volko, S.; Dong, X. The Arabidopsis NPR1 gene that controls systemic acquired resistance encodes a novel protein containing ankyrin repeats. Cell 1997, 88, 57-63. [CrossRef]

5. Shimono, M.; Sugano, S.; Nakayama, A.; Jiang, C.J.; Ono, K.; Toki, S.; Takatsuji, H. Rice WRKY45 plays a crucial role in benzothiadiazole-inducible blast resistance. Plant Cell 2007, 19, 2064-2076. [CrossRef]

6. Sugano, S.; Jiang, C.J.; Miyazawa, S.; Masumoto, C.; Yazawa, K.; Hayashi, N.; Shimono, M.; Nakayama, A.; Miyao, M.; Takatsuji, H. Role of OsNPR1 in rice defense program as revealed by genome-wide expression analysis. Plant Mol. Biol. 2010, 74, 549-562. [CrossRef]

7. Kachroo, P.; Shanklin, J.; Shah, J.; Whittle, E.J.; Klessig, D.F. A fatty acid desaturase modulates the activation of defense signaling pathways in plants. Proc. Natl. Acad. Sci. USA 2001, 98, 9448-9453. [CrossRef]

8. Shah, J.; Kachroo, P.; Nandi, A.; Klessig, D.F. A recessive mutation in the Arabidopsis SSI2 gene confers SAand NPR1-independent expression of $P R$ genes and resistance against bacterial and oomycete pathogens. Plant J. 2001, 25, 563-574. [CrossRef] [PubMed] 
9. Kachroo, P.; Kachroo, A.; Lapchyk, L.; Hildebrand, D.; Klessig, D.F. Restoration of defective cross talk in ssi2 mutants: Role of salicylic acid, jasmonic acid, and fatty acids in SSI2-mediated signaling. Mol. Plant Microbe Interact. 2003, 16, 1022-1029. [CrossRef] [PubMed]

10. Sekine, K.T.; Nandi, A.; Ishihara, T.; Hase, S.; Ikegami, M.; Shah, J.; Takahashi, H. Enhanced resistance to Cucumber mosaic virus in the Arabidopsis thaliana ssi2 mutant is mediated via an SA-independent mechanism. Mol. Plant Microbe Interact. 2004, 17, 623-632. [CrossRef]

11. Kachroo, A.; Fu, D.Q.; Havens, W.; Navarre, D.; Kachroo, P.; Ghabrial, S.A. An oleic acid-mediated pathway induces constitutive defense signaling and enhanced resistance to multiple pathogens in soybean. Mol. Plant Microbe Interact. 2008, 21, 564-575. [CrossRef] [PubMed]

12. Jiang, C.J.; Shimono, M.; Maeda, S.; Inoue, H.; Mori, M.; Hasegawa, M.; Sugano, S.; Takatsuji, H. Suppression of the rice fatty-acid desaturase gene OsSSI2 enhances resistance to blast and leaf blight diseases in rice. Mol. Plant Microbe Interact. 2009, 22, 820-829. [CrossRef] [PubMed]

13. HU, L.-q.; MU, J.-j.; SU, P.-s.; WU, H.-y.; YU, G.-h.; WANG, G.-p.; Liang, W.; Xin, M.; LI, A.-f.; WANG, H.-w. Multi-functional roles of TaSSI2 involved in Fusarium head blight and powdery mildew resistance and drought tolerance. J. Integr. Agr. 2018, 17, 368-380. [CrossRef]

14. Song, N.; Hu, Z.; Li, Y.; Li, C.; Peng, F.; Yao, Y.; Peng, H.; Ni, Z.; Xie, C.; Sun, Q. Overexpression of a wheat stearoyl-ACP desaturase (SACPD) gene TaSSI2 in Arabidopsis ssi2 mutant compromise its resistance to powdery mildew. Gene 2013, 524, 220-227. [CrossRef] [PubMed]

15. Vale, R.D. AAA proteins. Lords of the ring. J. Cell Biol. 2000, 150, F13-F19. [CrossRef] [PubMed]

16. Yedidi, R.S.; Wendler, P.; Enenkel, C. AAA-ATPases in protein degradation. Front. Mol. Biosci. 2017,4 , 42. [CrossRef]

17. Snider, J.; Houry, W.A. AAA+ proteins: Diversity in function, similarity in structure. Biochem. Soc. Trans. 2008, 36, 72-77. [CrossRef]

18. Sugimoto, M.; Yamaguchi, Y.; Nakamura, K.; Tatsumi, Y.; Sano, H. A hypersensitive response-induced ATPase associated with various cellular activities (AAA) protein from tobacco plants. Plant Mol. Biol. 2004, 56, 973-985. [CrossRef]

19. Lee, M.H.; Sano, H. Attenuation of the hypersensitive response by an ATPase associated with various cellular activities (AAA) protein through suppression of a small GTPase, ADP ribosylation factor, in tobacco plants. Plant J. 2007, 51, 127-139. [CrossRef]

20. Zhang, B.; Van Aken, O.; Thatcher, L.; De Clercq, I.; Duncan, O.; Law, S.R.; Murcha, M.W.; Van der Merwe, M.; Seifi, H.S.; Carrie, C. The mitochondrial outer membrane AAA ATPase AtOM66 affects cell death and pathogen resistance in Arabidopsis thaliana. Plant J. 2014, 80, 709-727. [CrossRef]

21. Zhu, X.; Yin, J.; Liang, S.; Liang, R.; Zhou, X.; Chen, Z.; Zhao, W.; Wang, J.; Li, W.; He, M. The multivesicular bodies (MVBs)-localized AAA ATPase LRD6-6 inhibits immunity and cell death likely through regulating MVBs-mediated vesicular trafficking in rice. Plos Genet. 2016, 12. [CrossRef] [PubMed]

22. Fekih, R.; Tamiru, M.; Kanzaki, H.; Abe, A.; Yoshida, K.; Kanzaki, E.; Saitoh, H.; Takagi, H.; Natsume, S.; Undan, J.R. The rice (Oryza sativa L.) LESION MIMIC RESEMBLING, which encodes an AAA-type ATPase, is implicated in defense response. Mol. Genet. Genom. 2015, 290, 611-622. [CrossRef] [PubMed]

23. Agrawal, G.K.; Rakwal, R.; Jwa, N.S. Rice (Oryza sativa L.) OsPR1b gene is phytohormonally regulated in close interaction with light signals. Biochem. Biophys. Res. Commun. 2000, 278, 290-298. [CrossRef] [PubMed]

24. Nakashita, H.; Yoshioka, K.; Takayama, M.; Kuga, R.; Midoh, N.; Usami, R.; Horikoshi, K.; Yoneyama, K.; Yamaguchi, I. Characterization of PBZ1, a probenazole-inducible gene, in suspension-cultured rice cells. Biosci. Biotechnol. Biochem. 2001, 65, 205-208. [CrossRef] [PubMed]

25. Wang, J.; Jiang, J.; Oard, J.H. Structure, expression and promoter activity of two polyubiquitin genes from rice (Oryza sativa L.). Plant Sci. 2000, 156, 201-211. [CrossRef]

26. Qi, M.; Yang, Y. Quantification of Magnaporthe grisea during infection of rice plants using real-time polymerase chain reaction and northern blot/phosphoimaging analyses. Phytopathology 2002, 92, 870-876. [CrossRef]

27. Huang, Q.N.; Shi, Y.F.; Zhang, X.B.; Song, L.X.; Feng, B.H.; Wang, H.M.; Xu, X.; Li, X.H.; Guo, D.; Wu, J.L. Single base substitution in OsCDC48 is responsible for premature senescence and death phenotype in rice. J. Integ. Plant Biol. 2016, 58, 12-28. [CrossRef]

28. Saifi, S.K.; Passricha, N.; Tuteja, R.; Tuteja, N. Stress-induced Oryza sativa RuvBL1a is DNA-independent ATPase and unwinds DNA duplex in 3' to 5' direction. Protoplasma 2018, 255, 669-684. [CrossRef] 
29. Lin, Y.; Tan, L.; Zhao, L.; Sun, X.; Sun, C. RLS3, a protein with AAA+ domain localized in chloroplast, sustains leaf longevity in rice. J. Integr. Plant Biol. 2016, 58, 971-982. [CrossRef]

30. Xia, Z.; Wei, Y.; Sun, K.; Wu, J.; Wang, Y.; Wu, K. The maize AAA-type protein SKD1 confers enhanced salt and drought stress tolerance in transgenic tobacco by interacting with Lyst-interacting protein 5. PLoS ONE 2013, 8. [CrossRef]

31. Wang, F.; Liu, J.; Chen, M.; Zhou, L.; Li, Z.; Zhao, Q.; Pan, G.; Zaidi, S.-H.-R.; Cheng, F. Involvement of abscisic acid in PSII photodamage and D1 protein turnover for light-induced premature senescence of rice flag leaves. PLoS ONE 2016, 11. [CrossRef] [PubMed]

32. Furukawa, T.; Ishibashi, T.; Kimura, S.; Tanaka, H.; Hashimoto, J.; Sakaguchi, K. Characterization of all the subunits of replication factor $\mathrm{C}$ from a higher plant, rice (Oryza sativa L.), and their relation to development. Plant Mol. Biol. 2003, 53, 15-25. [CrossRef] [PubMed]

33. Santos, L. Molecular mechanisms of the AAA proteins in plants. Adv. Agril. Food Biotechnol. 2006, 37, 1-15.

34. Zhang, P.; Zhang, Y.; Sun, L.; Sinumporn, S.; Yang, Z.; Sun, B.; Xuan, D.; Li, Z.; Yu, P.; Wu, W. The rice AAA-ATPase OsFIGNL1 is essential for male meiosis. Front. Plant Sci. 2017, 8, 1639. [CrossRef]

35. Shahriari, M.; Keshavaiah, C.; Scheuring, D.; Sabovljevic, A.; Pimpl, P.; Häusler, R.E.; Hülskamp, M.; Schellmann, S. The AAA-type ATPase AtSKD1 contributes to vacuolar maintenance of Arabidopsis thaliana. Plant J. 2010, 64, 71-85. [CrossRef]

36. Kaplan, C.P.; Thomas, J.E.; Charlton, W.L.; Baker, A. Identification and characterisation of PEX6 orthologues from plants. Bba-Mol. Cell Res. 2001, 1539, 173-180. [CrossRef]

37. Chung, K.; Tasaka, M. RPT2a, a 26S proteasome AAA-ATPase, is directly involved in Arabidopsis CC-NBS-LRR protein uni-1D-induced signaling pathways. Plant Cell Physiol. 2011, 52, 1657-1664. [CrossRef]

38. Su, Y.; Hu, S.; Zhang, B.; Ye, W.; Niu, Y.; Guo, L.; Qian, Q. Characterization and fine mapping of a new early leaf senescence mutant es3 (t) in rice. Plant Growth Regul. 2017, 81, 419-431. [CrossRef]

39. Xu, X.; Ji, J.; Xu, Q.; Qi, X.; Weng, Y.; Chen, X. The major-effect quantitative trait locus Cs ARN 6.1 encodes an AAA ATP ase domain-containing protein that is associated with waterlogging stress tolerance by promoting adventitious root formation. Plant J. 2018, 93, 917-930. [CrossRef]

40. Siebers, M.; Brands, M.; Wewer, V.; Duan, Y.; Holzl, G.; Dormann, P. Lipids in plant-microbe interactions. Bba-Mol. Cell Biol. L. 2016, 1861, 1379-1395. [CrossRef]

41. Lim, G.H.; Singhal, R.; Kachroo, A.; Kachroo, P. Fatty Acid- and Lipid-Mediated Signaling in Plant Defense. Annu. Rev. Phytopathol. 2017, 55, 505-536. [CrossRef] [PubMed]

42. Kachroo, A.; Venugopal, S.C.; Lapchyk, L.; Falcone, D.; Hildebrand, D.; Kachroo, P. Oleic acid levels regulated by glycerolipid metabolism modulate defense gene expression in Arabidopsis. Proc. Natl. Acad. Sci. USA 2004, 101, 5152-5157. [CrossRef] [PubMed]

43. Delteil, A.; Zhang, J.; Lessard, P.; Morel, J.-B. Potential candidate genes for improving rice disease resistance. Rice 2010, 3, 56. [CrossRef]

44. Haque, E.; Taniguchi, H.; Hassan, M.; Bhowmik, P.; Karim, M.R.; Śmiech, M.; Zhao, K.; Rahman, M.; Islam, T. Application of CRISPR/Cas9 genome editing technology for the improvement of crops cultivated in tropical climates: Recent progress, prospects, and challenges. Front. Plant Sci. 2018, 9, 617. [CrossRef] [PubMed]

45. Yang, W.; Dong, R.; Liu, L.; Hu, Z.; Li, J.; Wang, Y.; Ding, X.; Chu, Z. A novel mutant allele of SSI2 confers a better balance between disease resistance and plant growth inhibition on Arabidopsis thaliana. Bmc Plant Biol. 2016, 16, 208. [CrossRef] [PubMed]

46. Mandal, M.K.; Chandra-Shekara, A.; Jeong, R.-D.; Yu, K.; Zhu, S.; Chanda, B.; Navarre, D.; Kachroo, A.; Kachroo, P. Oleic acid-dependent modulation of NITRIC OXIDE ASSOCIATED1 protein levels regulates nitric oxide-mediated defense signaling in Arabidopsis. Plant Cell 2012, 24, 1654-1674. [CrossRef] [PubMed]

47. Moreau, M.; Lee, G.I.; Wang, Y.; Crane, B.R.; Klessig, D.F. AtNOS/AtNOA1 is a functional Arabidopsis thaliana cGTPase and not a nitric-oxide synthase. J. Biol. Chem. 2008, 283, 32957-32967. [CrossRef]

48. Miki, D.; Itoh, R.; Shimamoto, K. RNA silencing of single and multiple members in a gene family of rice. Plant Physiol. 2005, 138, 1903-1913. [CrossRef]

49. Miki, D.; Shimamoto, K. Simple RNAi vectors for stable and transient suppression of gene function in rice. Plant Cell Physiol. 2004, 45, 490-495. [CrossRef]

50. Toki, S.; Hara, N.; Ono, K.; Onodera, H.; Tagiri, A.; Oka, S.; Tanaka, H. Early infection of scutellum tissue with Agrobacterium allows high-speed transformation of rice. Plant J. 2006, 47, 969-976. [CrossRef] 
51. Yang, Y.; Qi, M.; Mei, C. Endogenous salicylic acid protects rice plants from oxidative damage caused by aging as well as biotic and abiotic stress. Plant J. 2004, 40, 909-919. [CrossRef] [PubMed]

52. Inoue, H.; Hayashi, N.; Matsushita, A.; Liu, X.; Nakayama, A.; Sugano, S.; Jiang, C.-J.; Takatsuji, H. Blast resistance of CC-NB-LRR protein $\mathrm{Pb} 1$ is mediated by WRKY45 through protein-protein interaction. Proc. Natl. Acad. Sci. USA 2013, 110, 9577-9582. [CrossRef] [PubMed]

53. Letunic, I.; Bork, P. Interactive Tree Of Life (iTOL) v4: Recent updates and new developments. Nucleic Acids Res. 2019, 47, W256-W259. [CrossRef] [PubMed]

(C) 2020 by the authors. Licensee MDPI, Basel, Switzerland. This article is an open access article distributed under the terms and conditions of the Creative Commons Attribution (CC BY) license (http://creativecommons.org/licenses/by/4.0/). 